\title{
Preferences and expectations among Polish women regarding prenatal screening
}

\author{
Przemyslaw Kosinski ${ }^{1}$, Jose Carlos PB Ferreiraa ${ }^{1,2}$, Michal Lipa ${ }^{1}$, Martyna Kajurek ${ }^{3}$, \\ Karolina Kurlenko ${ }^{3}$, Paulina Michalska ${ }^{3}$, Miroslaw Wielgos ${ }^{1}$ \\ ${ }^{1} 1$ st Department of Obstetrics and Gynecology, Medical University of Warsaw, Poland \\ ${ }^{2}$ Faculdade de Medicina, Universidade Eduardo Mondlane, Maputo, Mozambique \\ ${ }^{3}$ Students' Research Group, 1st Department of Obstetrics and Gynecology, Medical University of Warsaw, Poland
}

\begin{abstract}
Objectives: Patients' attitudes and expectations of prenatal screening for genetic abnormalities throughout pregnancy are rarely analyzed by researchers as emotions and fears are both important and challenging factors. Prenatal counselling has never been so difficult as we live in the era of detailed ultrasound scans, cell-free fetal DNA and detailed microarray testing. The aim of this study was to investigate Polish women's attitudes towards screening for chromosomal abnormalities and fetal defects.

Material and methods: The study was a prospective survey conducted among a population of Polish women. An electronic questionnaire regarding prenatal diagnostics was distributed to a total number of 1072 female volunteers.

Results: 1044 patients (97.30\%) stated that they were motivated to undergo prenatal diagnostics and would want to be informed about fetal abnormalities. Over $90 \%$ of the respondents would want to be informed about serious defects with a high mortality rate (including trisomy 13 or 18 ). More than half the Polish women $(54.83 \%)$ stated they were willing to consider terminating pregnancy in the case of a severe abnormality.

Conclusions: Polish women expect prenatal screening. Almost all Polish women would want to be informed about both genetic and anatomical abnormalities and over half of them would consider terminating pregnancy in the case of a severe abnormality. Willingness to learn about a defect increased with average household income, and the statement of a will to terminate pregnancy depended mostly on maternal age and type of fetal abnormality.
\end{abstract}

Key words: genetics; prenatal counselling; ultrasound

Ginekologia Polska 2019; 90, 9: 544-548

\section{INTRODUCTION}

Prenatal diagnostics has an important role in contemporary perinatal medicine. Structural defects or genetic disorders occur in approximately $3-5 \%$ of pregnancies. Such a high rate of adverse pregnancy outcomes points to the significance of prenatal diagnostics. In Poland the annual number of deliveries is approximately 400,000 . Considering the rate of $3-5 \%$ adverse outcomes, each year $12,000 \mathrm{ab}-$ normalities may occur in infants. However, different approaches exist to prenatal screening, invasive procedures and termination of pregnancy, due to personal and religious preferences [1, 2]. Major advances in prenatal medicine now offer a variety of diagnostic tools for parents expecting a baby. Medical professionals should always discuss all the options with patients. It has to be emphasized and properly acknowledged by medical professionals that not all patients expect exactly the same counselling and prenatal diagnosis. Does a perfect diagnostic algorithm for pregnant women exist at all? Do women want to be informed about all abnormalities? Which factors influence their attitude? Are the best diagnostic strategies for physicians perhaps not the most convenient for and acceptable to patients? This study aims to answer these questions and describe future parents' expectations towards prenatal diagnostics adjusted for their needs.

\section{MATERIAL AND METHODS}

The total number of patients who participated in this prospective survey was 1,072 . An electronic questionnaire regarding prenatal diagnostics was distributed to volunteers 
via social media and e-mails between November 2016 and March 2017. There was no specific algorithm for patient selection, but the only condition necessary for enrolment was access to the Internet and female gender. The consent for this survey study was obtained from all respondents. Demographic (age, ethnicity, chronic diseases), social (residence, education, religion, economic status) and obstetrical data were investigated. Further on in the questionnaire respondents were provided with a basic explanation of fetal abnormalities and intellectual disabilities (including trisomies 13, 18 and 21). Congenital anomalies were described in details and marked as five different types with decreasing severity and labeled as: type 1 (most die or handicapped if survive), type 2 (moderately handicapped, likely to have several common health problems), type 3 (health problems in only some of the individuals affected), type 4 (autism, intellectual disability) and type 5 (abnormal result of uncertain meaning). Description of abnormalities as presented in the questionnaire is summarized in Table 1. Questions regarding preferences for being informed about specific fetal disorders were asked. The local Ethical Committee of Warsaw Medical University (Poland) approved this study.

\section{Statistical analysis}

The data collected were cleaned, tabulated, and subjected to statistical analysis. Apart from the calculation of proportions and contingency tables, a series of $\mathrm{X}^{2}$ (Chi-Square) tests were performed in order to check for relationships between survey questions.

\section{RESULTS}

\section{Study group characteristics}

In total 1,072 women participated in the questionnaire. The majority of them were aged $25-29$ years (36.07\%) and $30-34$ years $(33.46 \%)$. The number of relatively younger (20-24 years) and older women (35-39 years) was comparable ( $12.24 \%$ and $12.18 \%$, respectively). Almost all ( 1,062 out of 1,072 ) of the women participating were born in Poland (99.07\%), as were most of their partners (described as "father of the baby") (96.45\%). The vast majority of respondents had

Table 1. Detailed description of abnormalities presented in the questionnaire

\begin{tabular}{|c|c|}
\hline $\begin{array}{l}\text { Type of } \\
\text { abnormality } \\
\text { detected } \\
\text { prenatally }\end{array}$ & Detailed description of abnormality \\
\hline Type 1 & $\begin{array}{l}\text { There are anomalies identified in some tests, which are surely known to cause problems for all the babies affected, and such problems } \\
\text { are so severe that most will not survive; that is, most babies affected with such anomalies, but not all, will die before they are born or } \\
\text { soon after being born. The few that survive will be very severely handicapped and will need complicated care while they live, for all } \\
\text { their lives, which will, most often, be short - examples of this type of anomalies are Trisomy 18, an anomaly that causes a disease } \\
\text { called syndrome of Edwards, and Trisomy 13, an anomaly that causes a disease called syndrome of Patau. }\end{array}$ \\
\hline Type 2 & $\begin{array}{l}\text { There are anomalies identified in some tests, which are surely known to cause problems for all the babies affected, although not as } \\
\text { severe as Type 1; most of the babies, in which those anomalies were detected, will survive. However, the vast majority of the surviving } \\
\text { babies will be moderately handicapped and will need someone taking some care of them for all their life, that may be long, although, } \\
\text { on average, slightly shorter than the population's average. They are more likely to have several common health problems throughout } \\
\text { their lives. Some, but not all, of those problems, will be treatable and cured, some partially repaired and some improved. There are } \\
\text { also interventions that may ameliorate their mental health, although not cure it. One frequently mentioned example of this type of } \\
\text { defect is Trisomy 21, a defect that causes a disease called Down syndrome. }\end{array}$ \\
\hline Type 3 & $\begin{array}{l}\text { There are anomalies identified in some tests, which are (not as surely as in type } 1 \text { or } 2 \text {, though) known to cause health problems in only } \\
\text { some of the individuals affected, but not in all. Even in those that will eventually develop health problems caused by the anomalies } \\
\text { identified by the tests, such health problems are generally considered by many people to be not very severe. For instance, babies, } \\
\text { in which those anomalies were detected by the tests and that will have health problems, may, when grown-ups, have abnormally } \\
\text { short or, reversely, tall stature, and are frequently infertile, that is, they cannot have babies on their own; sometimes it will be possible } \\
\text { to help them having babies, sometimes not. They may have, more frequently than other children, difficulties in school with some } \\
\text { disciplines, but many times get better with early intervention. Examples of this type of defect are some anomalies of the number of } \\
\text { the so-called sex chromosomes, the biological determinants of sex. }\end{array}$ \\
\hline Type 4 & $\begin{array}{l}\text { There are anomalies identified in some tests that make individuals carrying them more likely to develop some relatively severe } \\
\text { neurologic or psychiatric problems. This means that only a proportion of these babies that are found to have the test anomaly, but } \\
\text { not all, will develop certain mental diseases, such as autism, intellectual disability or schizophrenia, for example. That proportion may } \\
\text { vary with the test result but the exact value of that proportion may be imprecise and poorly known. Also, not all persons that will } \\
\text { eventually get affected will have equally severe diseases. Some individuals may have severe symptoms, some may have moderate } \\
\text { symptoms and some may have mild symptoms. It is important to also understand that only a small proportion of individuals with } \\
\text { autism, intellectual disability or schizophrenia will have this type of test defects. That is, if the baby test results are normal, that does } \\
\text { not mean that s/he will not have any of those conditions - autism, intellectual disability or schizophrenia. There are many causes for } \\
\text { these diseases, only a few of those causes are known, and from those, only a few can be detected by the tests. }\end{array}$ \\
\hline Type 5 & $\begin{array}{l}\text { There are anomalies identified in some tests, for which there are still not enough information to predict, with certainty, that the baby } \\
\text { will have a health problem. It will only be possible to say that, most likely, but not surely, the baby will have a health problem, although } \\
\text { it will not be possible to say which problem and its severity. }\end{array}$ \\
\hline
\end{tabular}


had higher education: $79.50 \%$ (57.05\% of partners), while $18.92 \%$ (39.03\% of partners) had had secondary education and $1.58 \%$ (3.92\% of partners) reported an elementary education level. More than $58 \%$ of the women taking part considered themselves religious, with over $71 \%$ being Christians (other religions: $7.55 \%$, no answer $20.55 \%$ ). Similar results concerned partners. A total of $43.04 \%$ women were pregnant, $6.91 \%$ within the 6 weeks after delivery and half (50.05\%) of the respondents were neither pregnant nor in the puerperium period. Within the group of pregnant respondents most women had been pregnant before (73.07\%), as opposed to women having their first babies (26.93\%). In total, $20.71 \%$ had had at least one spontaneous miscarriage and $4.38 \%$ of respondents had had a termination due to medical reasons. In $6.52 \%$ of cases fetal abnormalities of some sort had been detected, as opposed to $82.67 \%$ who had had no defects detected and $10.81 \%$ who did not answer this question.

\section{Patients' preference}

A total number of 1,044 participants (97.30\%) stated that they were motivated to undergo prenatal diagnostics of some kind as early as in the first trimester of pregnancy and in general would want to be informed about fetal abnormalities (without specifying exactly which defects - "the anomalies possible to detect in routine tests"); $2.7 \%$ of respondents would not want to be informed about these abnormalities. Within the group of women willing to undergo prenatal tests the percentages of women and their partners who considered themselves Christians were $96.73 \%$ and $97.24 \%$, respectively. Further on in the questionnaire fetal abnormalities were more precisely described. Over $90 \%$ of respondents would want to be informed about a very serious defect with a high mortality rate (including trisomy 13 or 18), as opposed to $2.61 \%$ who would want to be informed about such an abnormality only after delivery (and not during pregnancy). A total of $5.78 \%$ of respondents were not sure whether they would want to be informed during pregnancy or after delivery. The group of women who stated their wish to be informed about severe abnormality also stated that they would consider termination of pregnancy (54.83\%), as opposed to $15.71 \%$ who would not consider termination of pregnancy and $29.47 \%$ who were not sure what would they do in such circumstances. $92.72 \%$ of respondents would want to be informed about less serious defects with a low mortality rate (including life-long defects or health problems), as opposed to $3.26 \%$ who would want to be informed about such an abnormality only after delivery (and not during pregnancy). $0.19 \%$ of respondents would not want to be informed about such issues either before or after delivery. In cases of less severe health problems, $41.55 \%$ of patients would terminate the pregnancy, as opposed to $22.43 \%$ who would not consider pregnancy termination at all. As for the third type of abnormality described (only a certain number of children with minor health problems like infertility in adulthood, short stature or learning difficulties), $87.97 \%$ of respondents would want to be informed during pregnancy. In such circumstances, $7.21 \%$ participants would terminate the pregnancy, as opposed to $60.45 \%$ who would not consider pregnancy termination at all. In cases of less severe abnormalities (autism, schizophrenia, higher risk of health problems but in some cases no symptoms at all) $83.58 \%$ of respondents would want to be informed about these during pregnancy. In such circumstances, $6.58 \%$ patients would terminate the pregnancy, as opposed to $59.26 \%$ who would not consider pregnancy termination at all. In cases of health issues difficult to detect or confirm before birth, $75.02 \%$ of respondents would want to be informed about these during pregnancy. In such circumstances, $4.97 \%$ patients would terminate the pregnancy, as opposed to $62.86 \%$, who would not consider pregnancy termination at all. There is a relationship between income and the willingness for prenatal diagnosis of lethal defects $\left[X^{2}(12)=33,600, p=0.0008\right]$. Regardless of the average monthly income per household, the majority of respondents stated that they were willing to undergo prenatal diagnosis and would want to know about the type 1 defect ("the majority of neonates will die"). However, there was a tendency for willingness to learn about the defect to increase with average income ( $75 \%$ with an income of $<€ 250$, $87.1 \%$ with an income of $€ 250-500,88.9 \%$ with an income of $€ 500-1,000$ and $94.0 \%$ with an income of $>€ 1,000$ ). These data are presented in Table 2 . There is a relationship between income and the willingness for prenatal diagnosis of milder defects (type 3 ) $\left[x^{2}(12)=24,205, p=0.019\right]$. Regardless of the average monthly income per household, the majority of respondents stated they were willing to undergo prenatal diagnosis for defect 3. Regardless of parity, motivation to recognize defects with a different prognosis was the same for all respondents. Over $90 \%$ of patients would want to be tested for a type 1 defect, about $90 \%$ for type 2 , around $80-90 \%$ for type 3, around $80 \%$ for type 4 and around $70 \%$ for a type 5 defect. However, the trend is decreasing: the better the clinical prognosis for the defect, the fewer the patients (regardless of parity) stating their willingness for prenatal diagnosis of these conditions.

There is a relationship between the age of the respondents and their statement of willingness to terminate pregnancy in the case of a serious fetal abnormality $\left[X^{2}(19)=19,558 p=0.034\right]$. Willingness to terminate the pregnancy is most frequently stated by patients aged 40-44 (60\%), 35-39 (53.6\%) and 16-19 (42.8\%). These data are presented in Table 3.

It is not surprising that in the subgroup of women considering themselves Christian Catholics the percentage of 
Table 2. Relationship between stated willingness for prenatal tests concerning lethal defects and average monthly income per household $\left[X^{2}(12)=33,600, p=0.0008\right]$

\begin{tabular}{|c|c|c|c|c|c|}
\hline \multirow{7}{*}{$\begin{array}{l}\text { Stated willingness } \\
\text { to know if a fetus } \\
\text { has type } 1 \text { defect } \\
\text { (most children die, } \\
\text { individual cases } \\
\text { live until they } \\
\text { reach the age of } 1 \text { ) }\end{array}$} & & \multicolumn{4}{|c|}{ Average monthly income per household } \\
\hline & & $<€ 250$ & $€ 250-500$ & $€ 500-1,000$ & $>€ 1,000$ \\
\hline & I do not understand the question/ description of this type of defect & $0.00 \%$ & $1.61 \%$ & $0.47 \%$ & $0.00 \%$ \\
\hline & No, I would not like to know either during pregnancy or after delivery & $0.00 \%$ & $0.00 \%$ & $0.24 \%$ & $0.69 \%$ \\
\hline & $\begin{array}{l}\text { I am not sure whether I would like to know during pregnancy or after } \\
\text { delivery }\end{array}$ & $16.67 \%$ & $9.68 \%$ & $8.98 \%$ & $2.08 \%$ \\
\hline & $\begin{array}{l}\text { No, I would not like to know about it during pregnancy, but only after } \\
\text { delivery }\end{array}$ & $8.33 \%$ & $1.61 \%$ & $1.42 \%$ & $3.24 \%$ \\
\hline & Yes, I would like to know during pregnancy & $75.00 \%$ & $87.10 \%$ & $88.89 \%$ & $93.98 \%$ \\
\hline
\end{tabular}

Table 3. Relationship between age of respondents and their statement of willingness to terminate pregnancy in the case of type 2 fetal abnormality $\left[X^{2}(19)=19,558 p=0.034\right]$

\begin{tabular}{|c|c|c|c|c|c|c|c|}
\hline & & \multicolumn{6}{|l|}{ Age } \\
\hline & & 16-19 & $20-24$ & $25-29$ & $30-34$ & $35-39$ & $40-44$ \\
\hline \multirow{3}{*}{$\begin{array}{l}\text { Would you consider termination of } \\
\text { pregnancy if your type } 2 \text { defect was } \\
\text { confirmed (the majority of children survive } \\
\text { the neonatal period, but live with serious } \\
\text { defects that impair their quality of life)? }\end{array}$} & $\begin{array}{l}\text { No, I would most likely not choose this } \\
\text { option }\end{array}$ & $28.57 \%$ & $21.95 \%$ & $26.84 \%$ & $22.02 \%$ & $13.60 \%$ & $12.00 \%$ \\
\hline & I do not know what choice I would make & $28.57 \%$ & $39.02 \%$ & $37.29 \%$ & $36.90 \%$ & $32.80 \%$ & $28.00 \%$ \\
\hline & $\begin{array}{l}\text { Yes, I would consider termination in } \\
\text { such circumstances }\end{array}$ & $42.86 \%$ & $39.02 \%$ & $35.88 \%$ & $41.07 \%$ & $53.60 \%$ & $60.00 \%$ \\
\hline
\end{tabular}

respondents stating termination of pregnancy as a possibility is lower than in the entire population studied: the overall percentage of respondents declining pregnancy termination was $41.5 \%$, but in the Christian Catholic group it was $31.5 \%$.

\section{DISCUSSION}

The overall conclusion derived from an analysis of the survey is that in general Polish women desire prenatal diagnostics (97.30\%). It has to be underlined that Poland is considered a Catholic country with $88.8 \%$ of Poles identifying themselves as Roman Catholic in 2016 [census conducted by the Central Statistical Office (GUS)] [3]. This is also consistent with data gathered in this study — almost all respondents and their partners stated that they were Roman Catholics (96.73\% and $97.24 \%$, respectively). Polish women would definitely like to be informed about various health problems their baby might have, before the delivery. This study has several other interesting findings, many of which may differ from common assumptions regarding the population of women living in a homogeneous conservative country. For instance, more than half the respondents would consider termination of pregnancy for the most severe abnormalities like Patau and Edwards' syndrome (54.83\%) but not in cases of minor health problems like infertility, short stature or learning difficulties (7.21\%). In our study the less severe the defect, the lower the determination to detect the abnormality. This seems reasonable as couples who receive a diagnosis of unknown or uncertain significance may experience a difficult and stressful pregnancy though still have a final chance of having a healthy infant [4-6].

As expected, and as confirmed by other studies, advanced maternal age plays an important role in the decision to undergo prenatal diagnostic testing $[7,8]$. The statement of willingness to terminate pregnancy was stronger with advancing maternal age: $53 \%$ and $60 \%$ within age groups 35-39 and 40-44, respectively.

Prenatal counselling has never been so difficult. We live in the era of cell-free fetal DNA and detailed microarray testing. It is important to understand the benefits and the threads that can ensue from each possible screening and testing method [9]. But the most important thing is - to ensure patients understand their choices and receive accurate information and counselling before making informed decisions. This is even more important after realising that expectations of prenatal tests may be different for health professionals and for patients [10]. The study by Hill et al. [11] revealed that women placed a greater emphasis on test safety and having comprehensive information than health professionals, who placed more emphasis on accuracy and early testing than women. Unfortunately, patients'attitudes towards and expectations of prenatal diagnostics throughout pregnancy are rarely analysed by researchers as emotions and fears are important, challenging factors to be translated into scientific language [12]. 


\section{CONCLUSIONS}

The results of this study have important implications for health professionals and clinical management in Poland. Although the social, ethnic or religious background of a couple may alter the final decision on types of prenatal tests, almost all women in Poland $(97 \%)$ demand accessibility to prenatal testing. It has to be emphasised that there is also a group of women who are seeking prenatal testing primarily to obtain information without any intention to terminate pregnancy due to abnormal results.

\section{Study limitations}

This study has some limitations. The survey was an Internet-based study; it was distributed via e-mail and social media. Therefore, it has to be acknowledged that only women with a basic education, Internet and social media access would gain access to the survey. It has to be assumed that mostly women with a higher socio-economic status had access to the survey. As for all survey studies there is a selection bias related with the type of the study. It can never be accurately foreseen who will agree to participate therefore proper randomization in this case is not possible. It has to be acknowledged that this selection bias is a major weakness of this study. Although the authors took the greatest care to explain all the medical terms in the survey, some terms may not have been clear to patients who might have answered differently after further clarification. The strengths of this study include the large sample of both pregnant and non-pregnant women who provided the answers.

\section{Acknowledgements}

This research didn't receive grants from any funding agency in the public, commercial or not-for-profit sectors.

\section{REFERENCES}

1. Ngan OM, Yi H, Wong SY, et al. Obstetric professionals' perceptions of non-invasive prenatal testing for Down syndrome: clinical usefulness compared with existing tests and ethical implications. BMC Pregnancy Childbirth. 2017; 17(1): 285, doi: 10.1186/s12884-017-1474-6, indexed in Pubmed: 28870159.

2. Chen An, Tenhunen $\mathrm{H}$, Torkki $\mathrm{P}$, et al. Considering medical risk information and communicating values: A mixed-method study of women's choice in prenatal testing. PLoS One. 2017; 12(3): e0173669, doi: 10.1371/journal.pone.0173669, indexed in Pubmed: 28355226.

3. (GUS) CSO. Religion in Poland 2012-2014. Central Statistical Office of Poland (GUS) 2016

4. Hui L, Norton M. What is the real "price” of more prenatal screening and fewer diagnostic procedures? Costs and trade-offs in the genomic era. Prenat Diagn. 2018; 38(4): 246-249, doi: 10.1002/pd.5228, indexed in Pubmed: 29441593.

5. Canick J. Safety first: choices in antenatal screening for Down's syndrome. J Med Screen. 2003; 10(2): 55, doi: 10.1177/096914130301000201, indexed in Pubmed: 12831122.

6. Filly RA. Obstetrical sonography: the best way to terrify a pregnant woman. J Ultrasound Med. 2000; 19(1): 1-5, doi: 10.7863/jum.2000.19.1.1, indexed in Pubmed: 10625182.

7. Lichtenbelt KD, Schuring-Blom GH, van der Burg N, et al. Factors determining uptake of invasive testing following first-trimester combined testing. Prenat Diagn. 2013; 33(4): 328-333, doi: 10.1002/pd.4067, indexed in Pubmed: 23417693.

8. Godino L, Turchetti D, Skirton H. A systematic review of factors influencing uptake of invasive fetal genetic testing by pregnant women of advanced maternal age. Midwifery. 2013; 29(11): 1235-1243, doi: 10.1016/j.midw.2012.11.009, indexed in Pubmed: 23453699.

9. Green JM, Hewison J, Bekker HL, et al. Psychosocial aspects of genetic screening of pregnant women and newborns: a systematic review. Health Technol Assess. 2004; 8(33): iii, ix-x, 1, indexed in Pubmed: 15298822.

10. Bishop AJ, Marteau TM, Armstrong D, et al. Women and health care professionals' preferences for Down's Syndrome screening tests: a conjoint analysis study. BJOG. 2004; 111(8): 775-779, doi: 10.1111/j.1471-0528. 2004.00197.x, indexed in Pubmed: 15270923.

11. Hill M, Johnson JA, Langlois $S$, et al. Preferences for prenatal tests for Down syndrome: an international comparison of the views of pregnant women and health professionals. Eur J Hum Genet. 2016; 24(7): 968-975, doi: 10.1038/ejhg.2015.249, indexed in Pubmed: 26577044.

12. Allison SJ, Stafford J, Anumba DOC. The effect of stress and anxiety associated with maternal prenatal diagnosis on feto-maternal attachment. BMCWomens Health. 2011; 11:33, doi: 10.1186/1472-6874-11-33, indexed in Pubmed: 21749702. 